\title{
CARACTERÍSTICAS DA ARBORIZAÇÃO NA REGIÃO CENTRAL DO MUNICÍPIO DE COXIM, MS
}

\author{
Mariana Pereira Mota ${ }^{1}$; Luiz Fernando Rolim de Almeida ${ }^{2}$ \\ (recebido em 04.08.2010 e aceito para publicação em 15.03.2011)
}

\section{RESUMO}

A arborização exerce papel de vital importância para a qualidade de vida nos centros urbanos. Por suas múltiplas funções, a arborização urbana atua diretamente sobre o clima, a qualidade do ar, o nível de ruídos e sobre a paisagem, além de constituir refúgio indispensável à fauna remanescente nas cidades. A arborização urbana exige um planejamento criterioso e um manejo adequado para proporcionar benefícios. Entretanto, muitas cidades brasileiras não possuem tal planejamento, portanto muitos projetos baseiamse em métodos puramente empíricos. Foi feita a análise da arborização urbana do bairro São Judas Tadeu, onde foram encontradas 226 árvores com 17 espécies diferentes apresentando ataques de insetos como cupins e formigas, além de interferências na rede elétrica. As espécies Caesalpinea peltophoroides e Monquilea tomentosa representam 70\% do total de espécies encontradas, porém não são árvores indicadas para a arborização urbana trazendo consequências para a integridade das espécies e do ambiente urbano. $O$ uso inadequado da arborização acarreta vários prejuízos, além dos riscos de acidentes à população, pois exige que os órgãos prestadores de serviços públicos realizem podas periódicas, cortes drásticos e até mesmo a eliminação da vegetação existente.

Palavras-chave: arborização urbana, ambiente urbano, florística urbana, Coxim.

\footnotetext{
${ }^{1}$ Bióloga graduada no Curso de Ciências Biológicas da UEMS - Unidade de Coxim/MS. Rua General Mendes de Moraes, 370 - Jardim Aeroporto - CEP: 79400-000.

2 Docente Departamento de Ciências Biológicas - FCL - Assis/SP- UNESP. Avenida Dom Antonio, 2100 -

Parque Universitário - CEP: 19806-900. Fone: (18) 33025848 rolim@assis.unesp.br

*Trabalho de conclusão de curso para obtenção do título de Licenciada em Ciências Biológicas.
} 


\section{URBAN FOREST CHARACTERISTICS IN DOWN TOWN OF CITY OF COXIM, MS}

\section{ABSTRACT}

Urban forest plays a role of vital importance for quality of life in urban centers. Due to its multiple functions, urban forest acts directly on urban climate, air quality, level of noise and also on landscape, besides being essential refuge to remaining wildlife in the cities. Urban tree planting requires careful planning and a proper management to provide benefits. However, many Brazilian cities don't have this planning, thus many projects are purely based in empirical methods. Was done the analysis of urban forest in the neighborhood of São Judas Tadeu where were found 226 trees with 17 different species showing attacks by insects as termites and ants besides interferences in the power network. The species Caesalpinia peltophoroides and Monquilea tomentosa represent $70 \%$ of total species found, but these trees are not suitable for urban forest, bring consequences for the integrity of species and the urban environment. The use of improper species in urban tree planting carries several losses, beyond the risk of accidents to the population, because it requires that the public services providers perform periodic pruning, drastic cuts and even the removal of existing vegetation.

Keywords: urban forest, urban environment, urban floristic, Coxim.

\section{INTRODUÇÃO}

A arborização urbana é responsável pela melhoria da qualidade de vida da população nos centros urbanos. Assim, além da função paisagística, a arborização proporciona sombra para pedestres e veículos, redução da poluição sonora, melhoria na qualidade do ar, redução da amplitude térmica, abrigo para pássaros e equilíbrio estético. Esses fatores podem amenizar o impacto ambiental das grandes construções e projetos arquitetônicos que utilizam, de maneira geral, cimento, asfalto e estruturas metálicas. A percepção ambiental da arborização urbana e os benefícios para a população estão descritos nos trabalhos de Quadros e Frei (2009) e Isernhagen et al., (2009).

Entende-se por arborização urbana, o conjunto de terras públicas e privadas, com vegetação predominantemente que uma cidade apresenta, ou ainda, é um conjunto de (4) Pre

$\mathbf{S} \cdot \mathbf{B} \cdot \mathbf{A} \cdot \mathbf{U}$ Soc. Bras. de Arborização Urbana 
vegetação arbórea natural ou cultivada que uma cidade apresenta em áreas particulares praças, parques e vias públicas (SANCHOTENE, 1994; SILVA JUNIOR e MÔNICO,1994).

Para Lima et al. (1994), arborização urbana refere-se aos elementos vegetais de porte arbóreo dentro da cidade, tais como árvores e arbustos, plantados, inclusive em calçadas e praças.

Entretanto, em muitas situações o planejamento urbano deixa de incluir a arborização em suas prioridades, permitindo que iniciativas pontuais e desprovidas de conhecimento técnico atualizado leve a plantios irregulares de espécies sem compatibilidade com as áreas urbanas. Com isso ocorre a perda da eficácia da arborização em função dos inúmeros problemas e transtornos que iniciativas equivocadas trazem para a população e para o poder público.

Exemplos desses transtornos são o rompimento de fios de alta-tensão, interrupções no fornecimento de energia elétrica, entupimento em redes de esgoto, obstáculos para a circulação e acidentes envolvendo pedestres, veículos ou edificações. Portanto, a ausência de uma política sistemática e planejada com critérios paisagísticos tem trazido sérios problemas à população que solicitam ao poder público, constantemente, a autorização para a retirada e poda de copas e raízes das árvores que lhes causam transtornos.

Dentre as cidades brasileiras que foram estudadas no âmbito da arborização urbana destacam-se: Piracicaba-SP, Campos do Jordão-SP, Campina Grande-PB, Horizontina-RS, Nova Iguaçu-RJ, Pato Branco-PR; Mariópolis-PR; Sete de Setembro-RS; entre outros (MILANO, 1988; COLTRI, et al., 2005 e SILVA FILHO et al., 2008a; ANDRADE, 2002; DANTAS e SOUZA, 2004; FLORIANO, et al., 2004; ROCHA et al., 2004; SILVA et al. 2007, SILVA et al., 2008; COLETTO et al. 2008;).

O município de Coxim - MS está localizado no norte do Estado de Mato Grosso do Sul e situado no ecótono de transição de Cerrado e Pantanal. No município existem 17 bairros situados no perímetro urbano os quais apresentam escassa arborização e/ou plantios equivocados que acabam por perturbar tanto a população em função de danos causados nas residências. O presente trabalho foi realizado em um dos bairros do município (Bairro São Judas Tadeu) que foi escolhido em função de localizar-se na região central do município e englobar grande número de residências.

Para tanto os objetivos do trabalho foram levantar as espécies existentes, os aspectos fitossanitários e biológicos, bem como os principais impactos provocados pela arborização presente no Bairro.

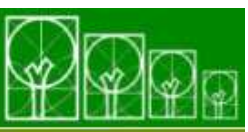

$\mathbf{S} \cdot \mathbf{B} \cdot \mathbf{A} \cdot \mathbf{U}$ Soc. Bras. de Arborização Urbana 


\section{MATERIAIS E MÉTODOS}

\section{Desenvolvimento da pesquisa de campo}

A partir do contato com a problemática estabelecida, busca-se atingir sua compreensão, ao mesmo tempo em que se faz uma interpretação da relação existente entre a arborização viária e o espaço que Ihe é destinado na área central da Cidade de Coxim. Portanto, a pesquisa foi realizada com o mapeamento das árvores situadas nas ruas, do bairro São Judas Tadeu da Cidade de Coxim - MS em 2007, por meio de formulário, para avaliação da situação fitossanitária e localização. Foi feito levantamento das condições da arborização urbana além da proposta de um plano de arborização para o município. Procedeu-se à adequação do formulário adaptado a partir de metodologias apresentadas por diferentes autores: Fischer, 1985; Milano, 1988; Oliveira e Kappel, 1994; Martins, 1994; Sanchotene, 2000; Santos e Teixeira, 1990; Takahashi, 1994; Vitória, 1992. Esse formulário passou a ser denominado de ficha de campo.

\section{Localização, identificação e mensuração}

O mapeamento foi iniciado com a localização da via pública, o número do imóvel (ordem crescente) onde se encontra a árvore, o bairro, o nome da árvore e a largura da rua e calçada. A estrutura arbórea deve ser avaliada pelas medições da planta como altura geral, altura da primeira ramificação e diâmetro do caule.

\section{Características biológicas e fitossanitárias de interesse}

Qualidade-condição geral da árvore; equilíbrio geral da árvore; fitossanidade com o diagnóstico do causador da doença ou injúrias; intensidade da agressão biológica; local do ataque feito pelos agentes biológicos e injúrias causadas por vandalismo. 


\section{RESULTADOS E DISCUSSÃO}

\section{Localização e Identificação}

Foram avaliadas e catalogadas 226 espécies arbóreas presentes na via pública do bairro São Judas Tadeu, região central do município de Coxim-MS. A predominância foram das espécies de Moquilea tomentosa (oiti) e Caesalpinea peltophoroides (Sibipiruna) que representam aproximadamente $70 \%$ das plantas do bairro (Tabela 1). Essas espécies são consideradas abundantes em outros tabalhos de arborização urbana segundo Silva Filho et al. (2002) e Silva et al. (2002) que indicam a baixa diversidade de espécies utilizadas em áreas urbanas e a elevada abundância destas que implica na homogeinização da paisagem urbana e favorece o ataque de patógenos e herbívoros.

TABELA 1. Espécies encontradas no bairro São Judas Tadeu da cidade de Coxim, MS.

TABLE 1. Species found in neighborhood of São Judas Tadeu of city of Coxim, MS.

\begin{tabular}{llccc}
\hline NOME POPULAR & \multicolumn{1}{c}{ NOME CIENTÍFICO } & FAMILIA & QUANTIDADE & $\%$ \\
\hline Oiti & Moquilea tomentosa & Chrysobalanaceae & 80 & 35,40 \\
Sibipiruna & Caesalpinea peltophoroides & Fabaceae & 77 & 34,07 \\
Ficus & Ficus sp & Moraceae & 15 & 6,64 \\
Monguba & Pachira aquática & Malvaceae & 15 & 6,64 \\
Flamboyan & Delonix regia & Fabaceae & 6 & 2,65 \\
Murta & Murraya exótica & Rutaceae & 4 & 1,77 \\
Mangueira & Mangifera indica & Anacardiaceae & 4 & 1,77 \\
Tamarindo & Tamarindus indica & Fabaceae & 3 & 1,33 \\
Barriguda & Chorisia crispiflora & Malvaceae & 2 & 0,88 \\
Pingo de Ouro & Duranta repens & Verbenaceae & 2 & 0,88 \\
Ipê & Tabebuia sp & Bignoniaceae & 2 & 0,88 \\
Tamburi & Enterobium timbouva & Fabaceae & 1 & 0,44 \\
Cambucá & Plinia edulis & Myrtaceae & 1 & 0,44 \\
Pitangueira & Eugenia uniflora & Myrtaceae & 1 & 0,44 \\
Jenipapo & Genipa americana & Rubiaceae & 1 & 0,44 \\
Sete-copas & Terminalia catapa & Combretaceae & 1 & 0,44 \\
Jatobá & Hymenaea courbaril & Fabaceae & 1 & 0,44 \\
não identificada & & & 2 & 0,88 \\
\hline
\end{tabular}

De acordo com as recomendações de Grey e Deneke (1978), citados por Milano e Dalcin (2000), cada espécie não deve ultrapassar 10-15\% do total de indivíduos da população arbórea, para um bom planejamento da arborização urbana. Além disso, a predominância de apenas uma espécie ou grupo de espécies pode facilitar a propagação das pragas, atualmente muito comum nas árvores em ambiente urbano. 
De acordo com a Figura 1, a rua Joaquim Cardeal de Souza apresenta maior número de árvores estando predominantemente presente do lado esquerdo, local oposto ao dos postes e materiais da empresa de energia elétrica da região. De modo geral encontramos árvores plantadas em locais apropriados em vias de grande porte, sendo que em ruas mais estreitas essa disposição das árvores não foi observada. As ruas Campo Grande, Belém e Porto Alegre são as ruas que apresentam baixo número de árvores. Nas demais ruas a quantidade de árvores se mantiveram mais ou menos na mesma proporção. Foi encontrada pouca diversidade de espécies, onde muitas apresentaram limitações para a arborização urbana do bairro, portanto não são recomendadas para o plantio em vias públicas. De acordo com Enersul (2005), os aspectos estéticos da arborização devem ser observados principalmente em relação aos novos plantios de uma única espécie em uma determinada via, variando a espécie de uma rua para outra, a fim de manter a biodiversidade.

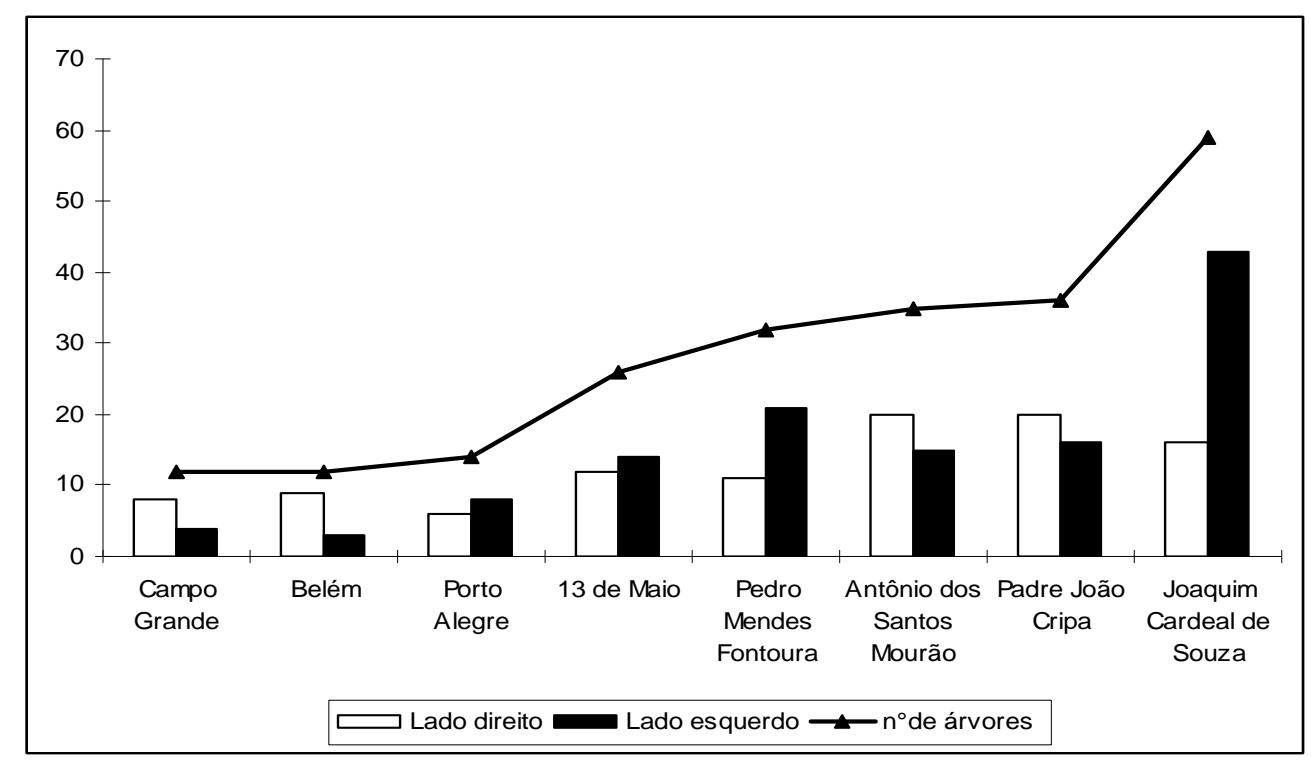

FIGURA 1 - Distribuição das árvores pelas ruas do bairro São Judas Tadeu.

FIGURE 1 - Distribution of trees in streets of São Judas Tadeu neighborhood.

A maioria das ruas do bairro São Judas Tadeu podem ser consideradas ruas estreitas, pois apresentam larguras no máximo de 8 metros. Assim, recomenda-se plantio nessas ruas de espécie de pequeno porte, podendo ser plantadas apenas de um lado da calçada ou alternadamente com espaçamento de plantio recomendado de 15 metros entre árvores. A rua Joaquim Cardeal de Souza apresenta largura de 14,10 metros, a mesma tem a presença de canteiro central o qual pode ser arborizado com o plantio de espécies de médio a grande porte.

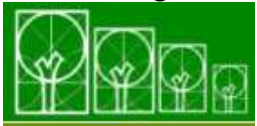

$\mathbf{S} \cdot \mathbf{B} \cdot \mathbf{A} \cdot \mathbf{U}$ Soc. Bras. de Arborização Urbana 
A altura geral e altura da primeira ramificação das espécies estudadas a média foi de $7,80 \mathrm{~m}$ e $1,10 \mathrm{~m}$ respectivamente, sendo que o perímetro do caule a média foi de $0,86 \mathrm{~m}$ (Figura 1).

Embora o valor médio desses parâmetros indiquem a dimensão das árvores estudadas, é importante verificar também qual a relação que existe entre esses parâmetros comparando o total de espécies arbóreas levantadas. Para isso a Figura 2 mostra o total das espécies dispostas em ordem crescente em relação ao parâmetro altura (linha espessa e contínua) chegando a indicar árvores com até $20 \mathrm{~m}$ de altura. O gráfico mostra espécies com alturas maiores, porém não indica a tendência de caules mais espessos e ramificações primárias mais elevadas. Esses dados indicam a idade aproximada das espécies bem como pode levar a previsões a respeito do tempo de vida das árvores, sendo importante instrumento para o planejamento e avaliação da arborização urbana.

Assim, pode-se considerar que o plantio de árvores no bairro, ou é recente, uma vez que as espécies são de grande porte, e portanto, tem muito para crescer, ou que o referido plantio sofreu várias podas drásticas e por isso apresentam- se com seu porte reduzido.

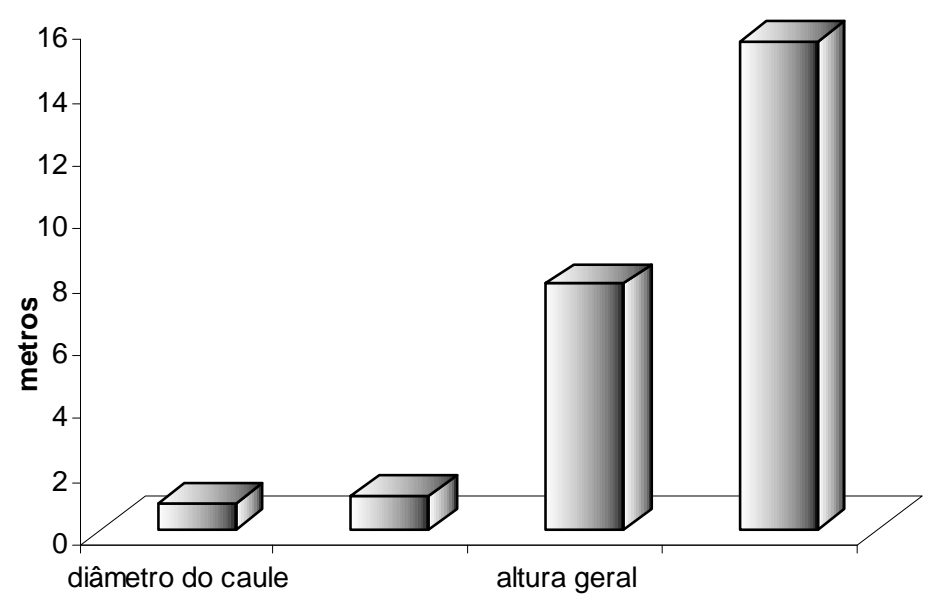

FIGURA 2 - Média dos parâmetros de dimensão das árvores estudadas.

FIGURE 2 - Average of dimension parameters of studied trees. 


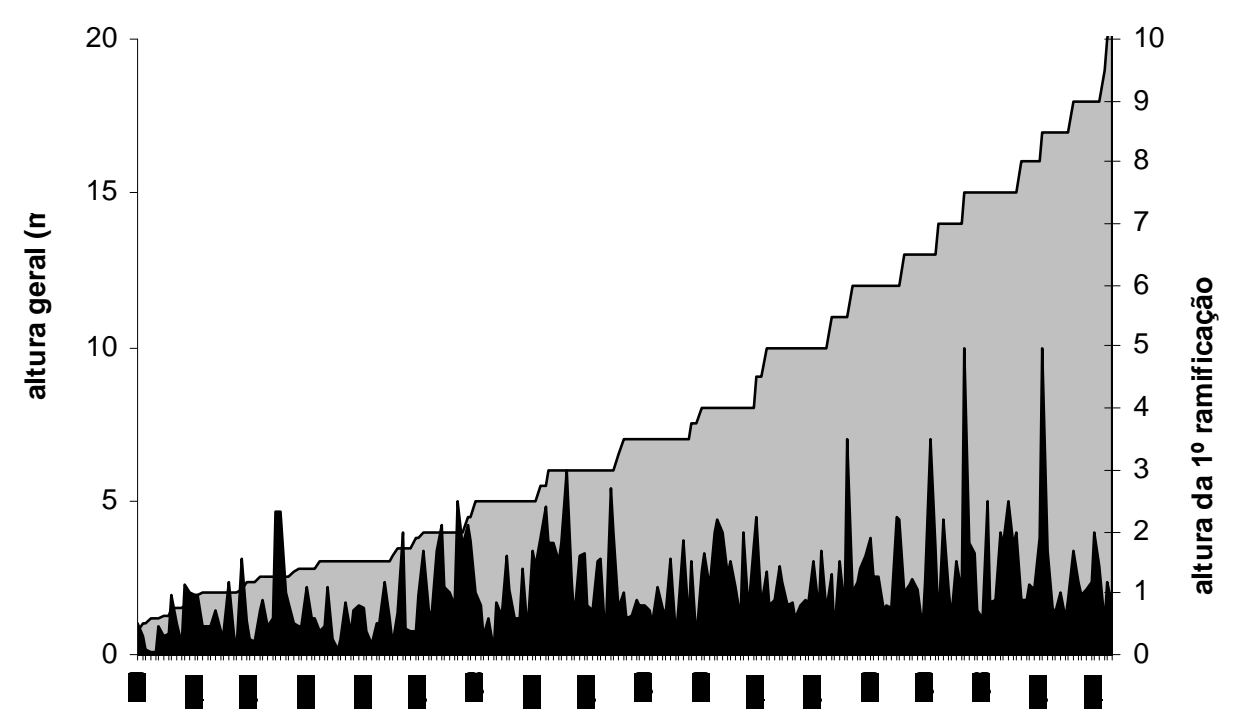

lista das espécies

पalturageral $\quad$ altura ramificação

FIGURA 3 - Perfil do total de espécies estudadas. No eixo $X$ estão todas as espécies levantadas em ordem crescente de altura geral. $O$ eixo $Y$ (esquerdo) refere-se a altura geral e o eixo y (direita) altura da $1^{\circ}$ ramificação .

FIGURE 3 - Profile of total studied species. In X-axis are all species raised in ascending order of overall height. The $\mathrm{Y}$-axis (left) refers to overall height and the $\mathrm{Y}$-axis (right) refers to height of first branch.

\section{Aspectos biológicos e fitossanitários}

A Figura 4 mostra o estado geral das árvores, sendo que das 226 árvores analisadas nesta área 59,5\% apresentaram estado geral bom e ótimo sendo que 16\% são árvores em estado regular, onde apresentam início de declínio, com severos ataques de insetos e injúria mecânica, descaracterizando sua arquitetura ou desequilibrando o vegetal. Já $23 \%$ das árvores estão em estado péssimo, ou seja, em um avançado e irreversível declínio, apresenta ataques severos de cupins, formiga e insetos, além de injúrias mecânicas que não podem ser sanados com a utilização de podas pois não resultará na recuperação do vegetal. Ainda $0,4 \%$ dos casos é de morte das árvores.

A Figura 5 mostra o equilíbrio geral das árvores, onde $81 \%$ das árvores está em equilíbrio, com caule ereto e copa de mesmas proporções para todos os lados. E 19\% não está em equilíbrio, caule e copa não apresenta mesmas proporções para todos os lados. $\mathrm{Na}$ 
Figura 6 representa as árvores que não estã equilíbrio geral, onde 53\% dos casos é a copa que não está em equilíbrio e $47 \%$ é o caule, não está ereto e na mesma proporção para todos os lados.

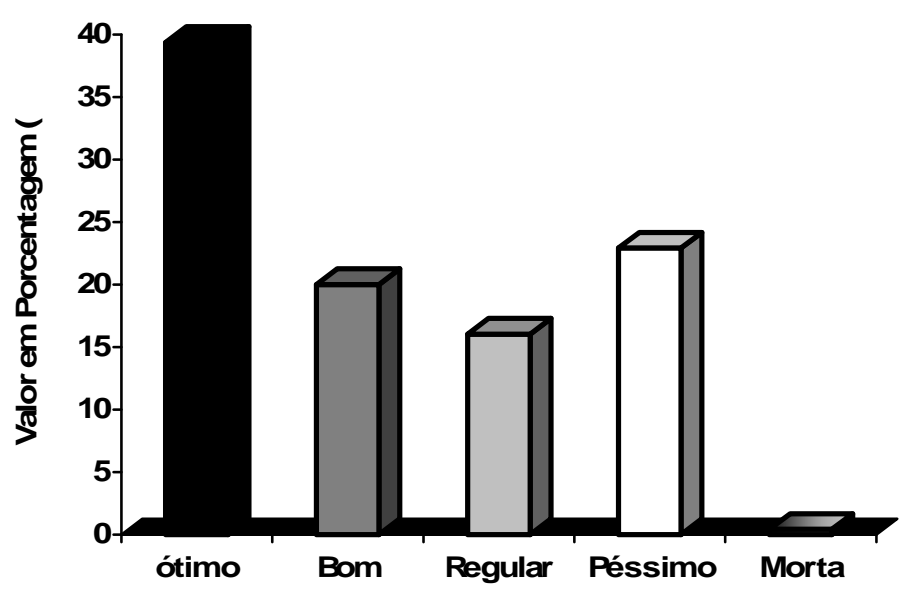

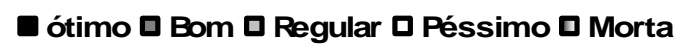

FIGURA 4 - Estado geral das árvores do bairro São Judas Tadeu.

FIGURE 4 - General condition of trees in neighborhood of São Judas Tadeu.

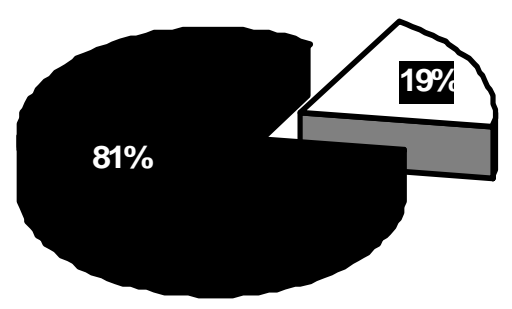

\section{Q Năo — Sim}

FIGURA 5 - Equilíbrio geral das árvores.

FIGURE 5 - General balance of trees.

Esses dados indicam que a maoiria das espécies estudadas podem ser mantidas através de podas de controle (formação, limpeza, emergência e adequação) fato que manterá o estado geral em condições satisfatórias para a manutenção do vegetal. Porém, outras espécies devido a sua descaracterização do perfil geral e más condições de conservação nesessitam de podas drásticas, pois tais espécies não retomarão seu crescimento normal em função dos danos ocorridos. As condições que englobam o perfil geral das árvores parece ser uma das principais preocupações da população frente ao tema 
Arborização Urbana, pois segundo Oliveira (2005), a população considera árvores muito velhas e que precisam cuidados especiais, ou mesmo do corte, como sendo prioridades para evitar acidentes e aproximar a comunidade dos cuidados com a arborização.

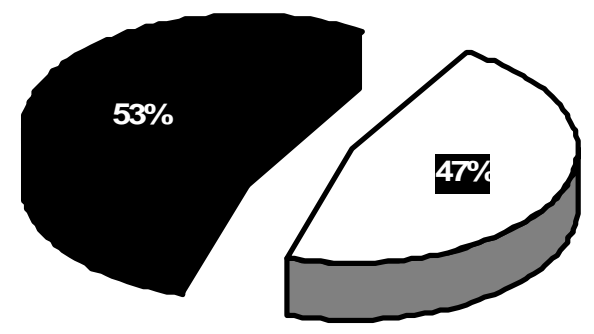

\section{Q Caule D Copa}

FIGURA 6 - Porcentagem das árvores que não estão em equilíbrio geral em função do órgão vegetativo responsável pelo desequilíbrio.

FIGURE 6 - Percentage of trees that aren't in general balance in function of vegetative organ response to imbalance.

A Figura 7 indica que o estado fitossanitário das espécies estudadas é afetado principalmente por cupins e formigas que podem danificar o corpo do vegetal e levar a outras conseqüências mais graves como afetar o equilíbrio geral. A Figura 8 mostra a intensidade da agressão dos organismos nas árvores, com 9,2\% a intensidade é leve, pois, o organismo ou agente está presente, porém sem causar danos à árvore. A intensidade média é de $57 \%$, onde o organismo está presente, causando danos reparáveis às árvores. $\mathrm{E}$ 28,3\% das agressões são de intensidade pesada, o organismo ou agente está causando danos graves, que podem levar as árvores a um declínio irreversível. 


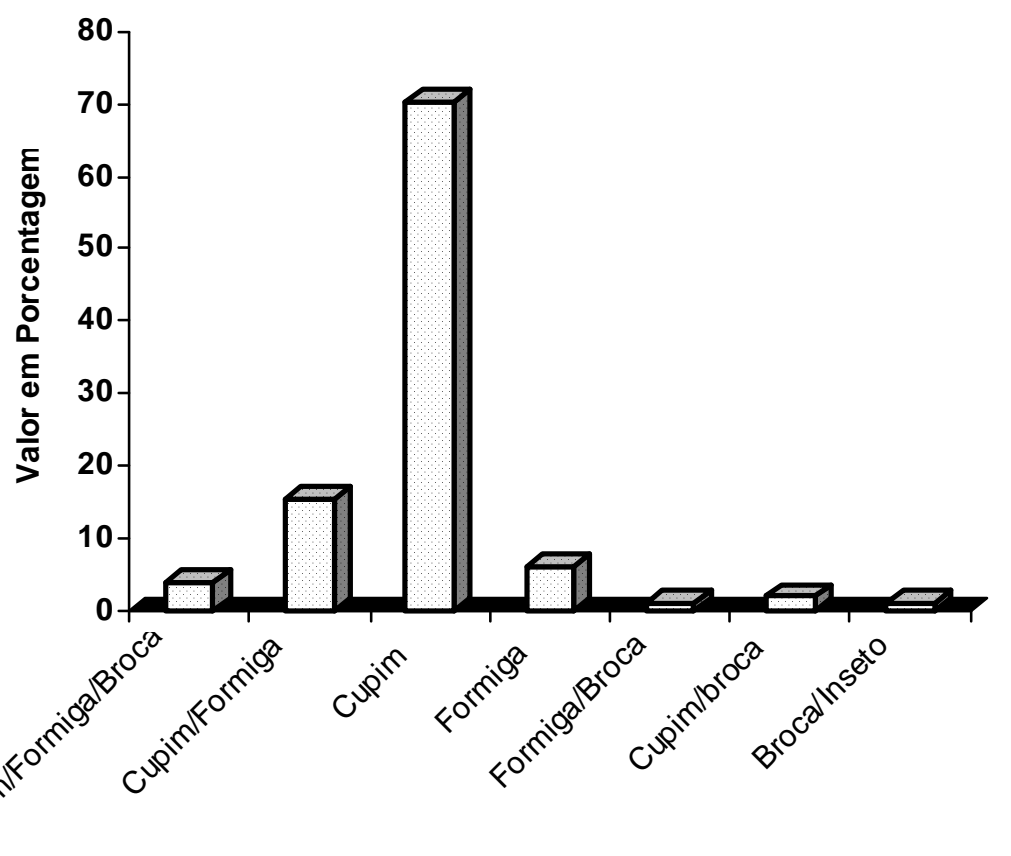

FIGURA 7 - Fitossanidade - diagnóstico do causador da doença ou injúria.

FIGURE 7 - Phytosanity - diagnostic of disease or injury causing agents.

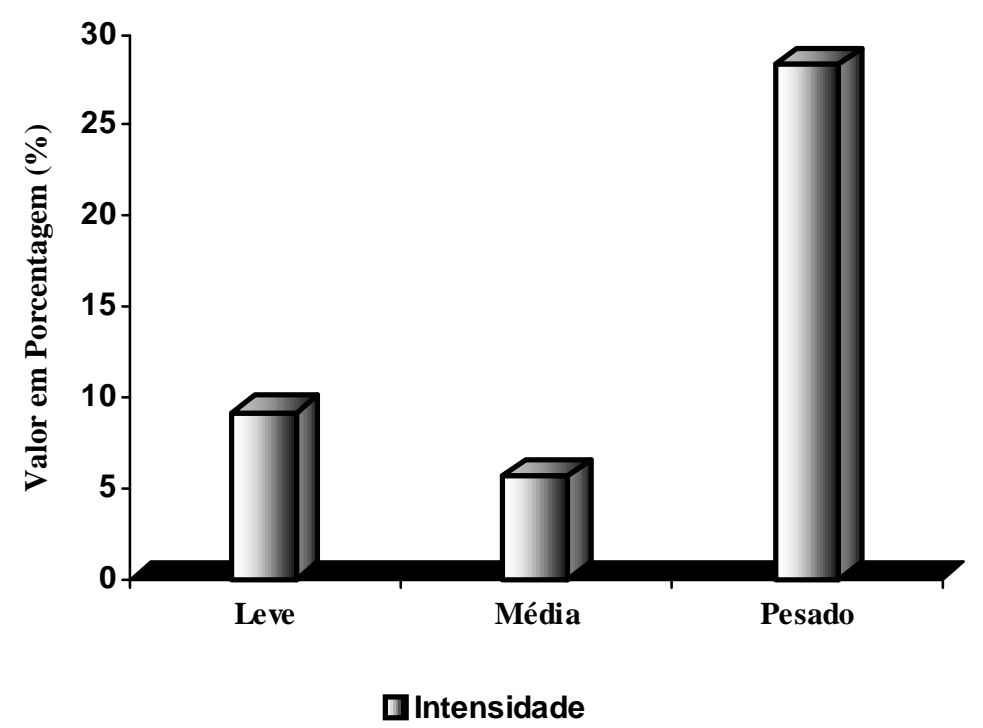

FIGURA 8 - Intensidade de ataques em relação a fitossanidade.

FIGURA 8 - Intensity of attacks in relation to phytosanity.

Segundo Bortoleto e Filho (2006), verificaram que os indivíduos da arborização viária de Estância de Águas de São Pedro - SP apresentaram baixa porcentagem referente a lesões (leve, média e grave), se deu pelo baixo índice de podas realizadas no município, e 
que estas quando realizadas quantificam as lesões graves, por serem drásticas e proporcionarem a presença de cupins. Segundo Hasse et al. (2008) a existência e cupins ou outros parasitas leva a um alto risco de queda do espécime, pois os danos físicos comprometem as propriedades físicas e mecânicas diminuindo a resistência da árvore. Ainda, segundo Ruschel e Leite (2002) o grau de infestação foi diagnosticado quantitativamente no trabalho realizado em Lajeado-RS, onde a presença de um ou mais hemiparasitas parece indicar uma sucessão de erros no planejamento da arborização urbana como podas e plantios em locais impróprios.

A Figura 9 mostra que as maiorias das espécies arbóreas analisadas sofreram lesões do tipo leve correspondendo 34,9\% dos casos, ou seja, injúria de pequena relevância onde a árvore pode conseguir sua recuperação sem qualquer intervenção. Já 34,5\% dessas árvores não apresentaram nenhum tipo de lesão correspondendo $34,5 \%$, porém as lesões de intensidade grave foram de $16 \%$, onde a árvore está com sua sobrevivência comprometida. As lesões médias foram de 14,6\%, a injúria não é de grande intensidade, mas necessita de cuidados mediante ações de controle. O local das árvores que foram atacados por determinadas pragas (cupins, formigas, insetos, broca), sendo $100 \%$ o caule 0 local de ataque. Entretanto, algumas espécies em certas condições tornam-se pragas, um exemplo é o cupim que atacam mudas ou árvores vivas e ocasiona a destruição do sistema radicular, morte das mudas ou perda da qualidade da madeira.

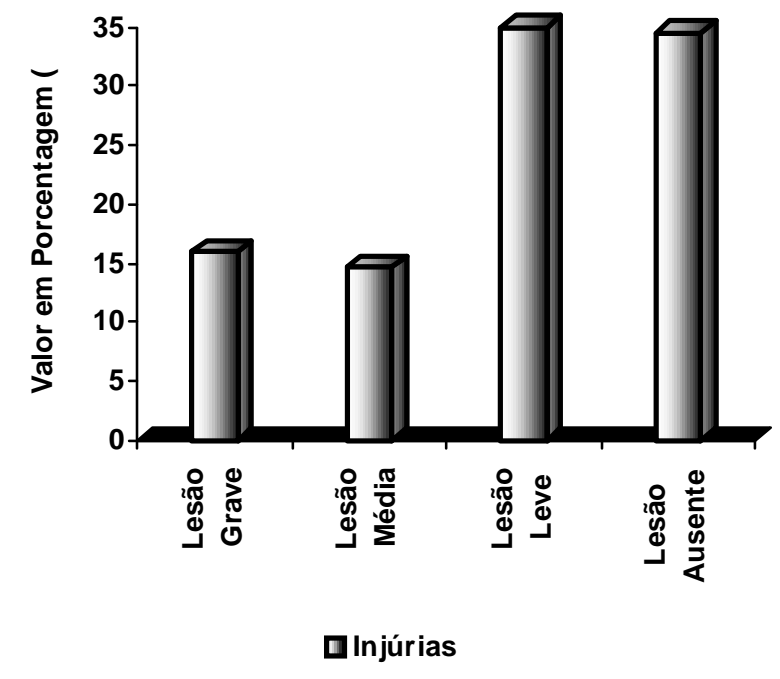

FIGURA 9 - Intensidade de injúrias caudadas por vandalismo nas espécies arbóreas.

FIGURE 9 - Intensity of injuries caused by vandalism in arboreal species.

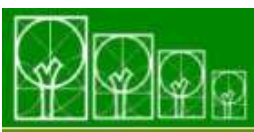


A Figura 10 mostra as relações simbióticas com outros organismos indicando a presença de liquens no caule das árvores. Os liquens são uma associação entre algas e fungos onde as algas realizam 0 processo fotossintético fixando carbono em macromoléculas e os fungos utilizam essas substâncias, mas protegem o vegetal contra a dessecação que a sazonalidade ambiental impõe. Segundo Odum (1998), os líquens são indicadores de poluição ambiental sendo encontrados em áreas que apresentam condições satisfatórias de poluição atmosférica.

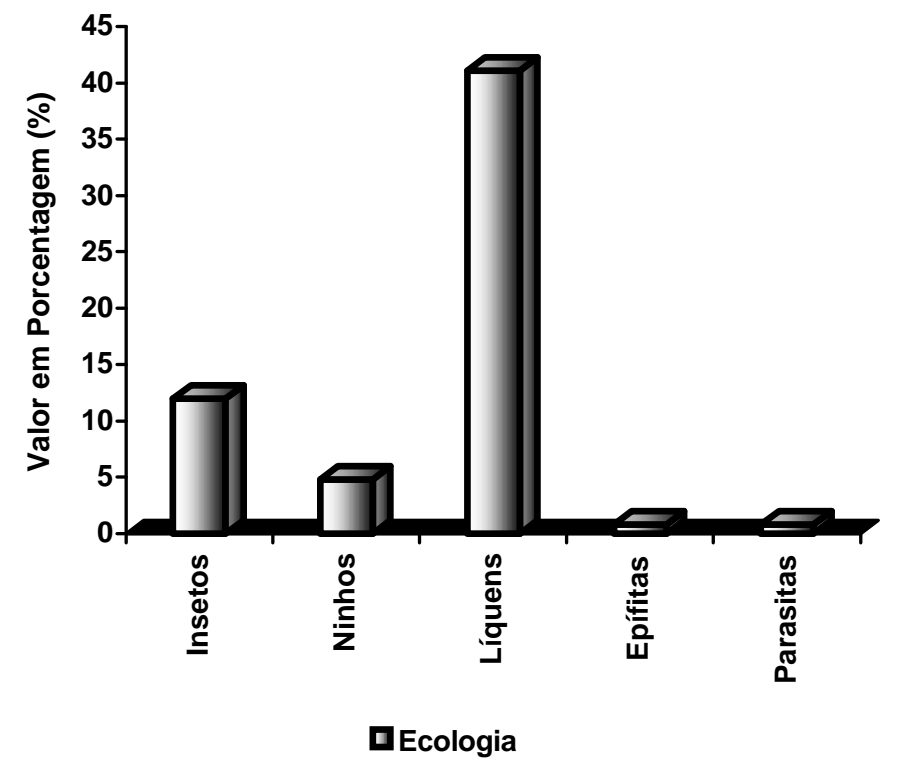

FIGURA 10 - Ecologia das árvores.

FIGURE 10 - Ecology of trees.

A Figura 11 mostra a estrutura biológica das árvores, onde 99,5\% das árvores analisadas apresentaram folhas, as mesmas são de importância vital para as árvores, pois, elas funcionam como laboratório vegetal, que captam a energia solar e transformam em substâncias orgânicas a água e os sais minerais absorvidos do solo, e o gás carbônico retirado do ar, e assim realizar a fotossíntese. E 14,1\% das árvores tinham flores o que representa que as árvores estavam em período de reprodução, além de contribuir com a beleza plástica do bairro. Com $12,8 \%$ são as árvores com frutos o caracteriza o resultado da reprodução das flores e também representa um atrativo para avifauna e/ou, com efeito, ornamental. 


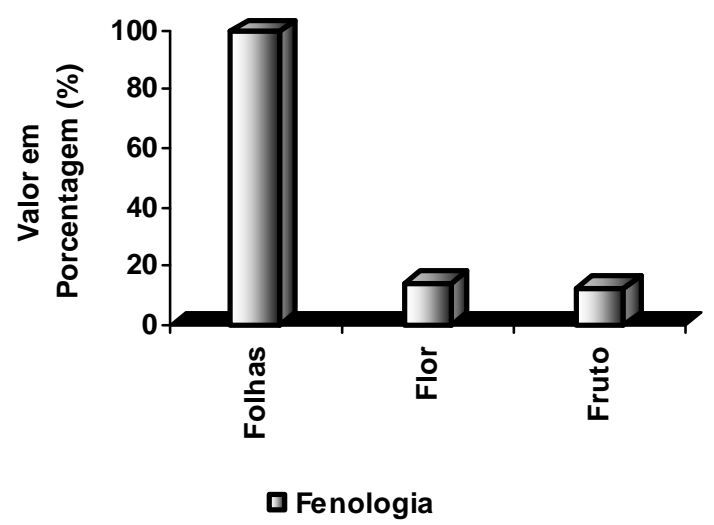

FIGURA 11 - Fenologia das árvores.

FIGURE 11 - Phenology of trees.

\section{Entorno e Interferências}

A Figura 12 mostra o local onde foram encontradas as árvores do bairro sendo que das 226 árvores analisadas, 95,5\% estavam localizadas nas calçadas e apenas 4,5\% em canteiro central. A Figura 13 complementa que nas calçadas a posição mais utilizada para o plantio é junto à guia (61\%) e no centro da calçada (45\%). Da mesma maneira Silva et al. (2002) estudando a posição em que as árvores foram plantadas, pode-se constatar o predomínio do plantio no meio fio e no centro da calçada. Segundo o autor, o plantio no meio fio evita problemas com construções e residências, mas pode gerar problemas nas ruas e até mesmo para os pedestres.

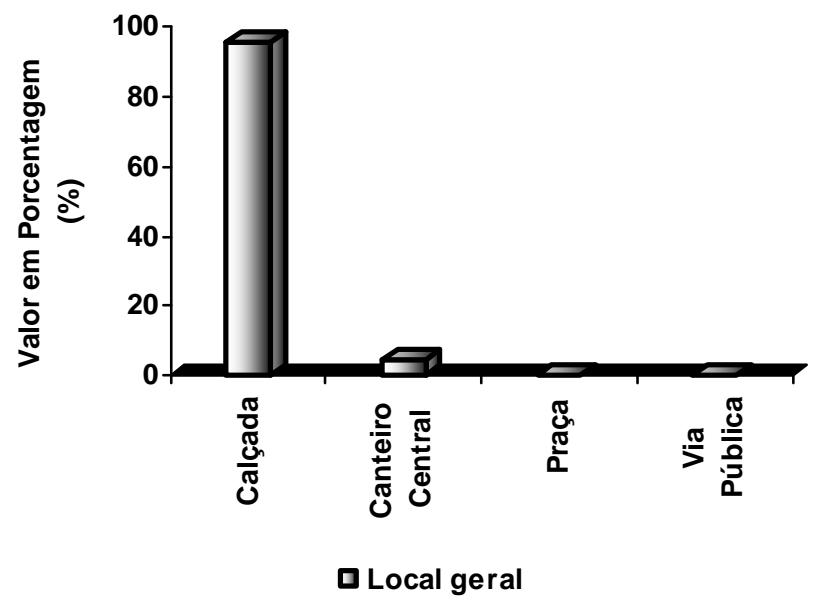

FIGURA 12 - Local onde estão localizadas as árvores do bairro.

FIGURE 12 - Location of trees in neighborhood. 


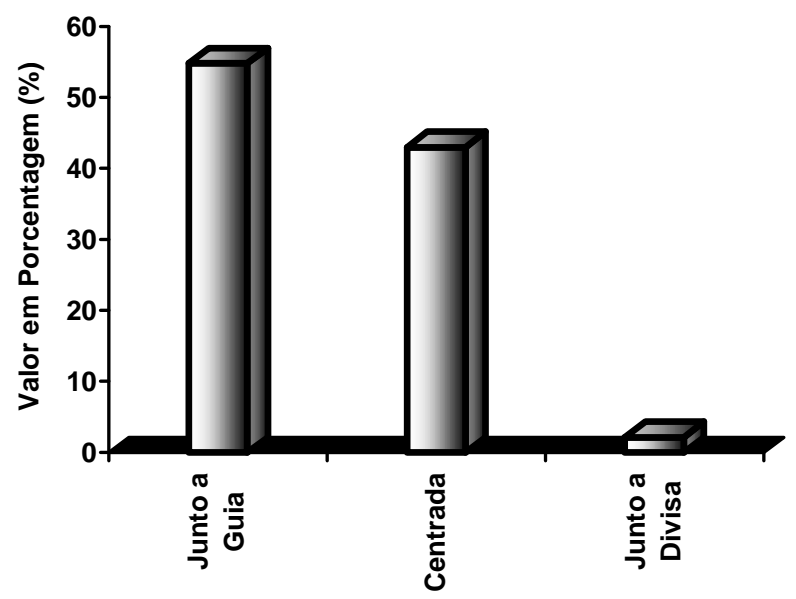

FIGURA 13 - Localização relativa das espécies arbóreas.

FIGURE 13 - Relative localization of arboreal species.

A Figura 14 mostra que maioria encontra-se sobre substrato de terra, isto é, solo típico da região do município de Coxim, correspondendo $49,5 \%$ dos casos, já $46,5 \%$ foram encontradas no substrato de cimento e $3 \%$ no substrato de cerâmica os quais não são favoráveis para o desenvolvimento do vegetal, pois, o cimento bem como a cerâmica são materiais que abafam a raiz restringindo o crescimento da mesma na busca de água. Ao contrário dos mesmos, apenas $1 \%$ foram localizadas na grama, sendo ideal para 0 desenvolvimento do vegetal, pois os eventuais danos como afloramento de raiz nas calçadas ficariam restritas apenas as faixas gramadas. Essa característica permite uma maior absorção e penetração de água da chuva possibilitando maior respiração do solo.

Assim, pode-se observar que a grande maioria das árvores do bairro estavam localizadas em calçadas inteiramente fechadas, sendo poucas encontradas nas faixas verdes. Essa característica fechada das calçadas proporciona sérios problemas nas árvores, tais como perda de vigor, aparecimento de cupins nas raízes e troncos, doenças degenerativas e envelhecimento precoce. 


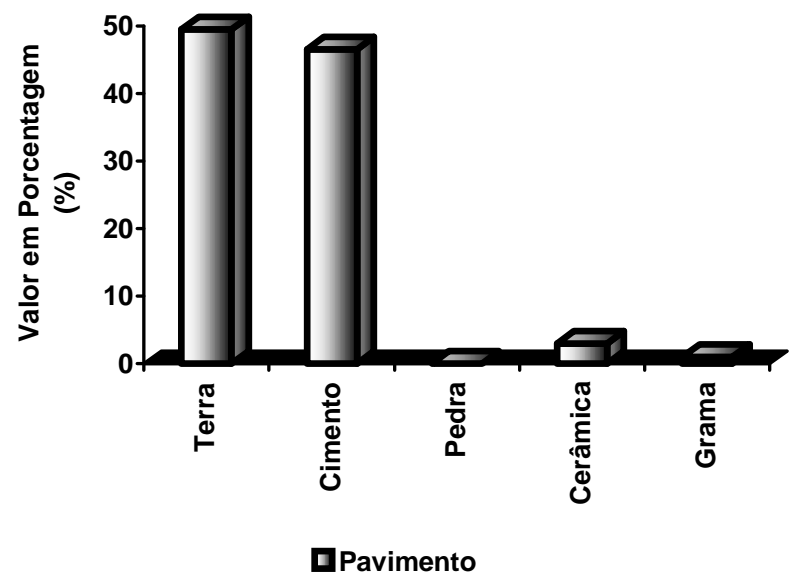

FIGURA 14 - Distribuição das espécies arbóreas no cenário urbano.

FIGURE 14 - Distribution of arboreal species in urban scenery.

A Figura 15 mostra que é nas calçadas o maior índice de afloramento de raíz representando $22,5 \%$ dos casos e em canterios o afloramento foi de $2,6 \%$, isso se explica porque o afloramento da raiz é provocado freqüentemente por área livre reduzida para o crescimento dos indivíduos. De acordo com Sirkis (1999), os casos em que em que as raízes quebram as calçadas, em geral, são ocasionados por insuficiente espaço livre para penetração de água e ar. Este mesmo autor sugere que para árvores com altura superior a seis metros, essa área livre deve ter no mínimo $4 \mathrm{~m}^{2}$ para seu desenvolvimento. Como nos alerta Lorenzi (2001 p.12), "é preciso planejamento". (...) "é lógico que a maioria das cidades não são planejadas e o espaço existente para as árvores exíguo", por outro lado, "é incoerente plantar árvores e considerá-las como postes, talvez por confundi-las, é comum na cidade a calçada encostada nos troncos. Não tem área para absorção e infiltração da água". Para evitar tais problemas em futuros plantios, devem-se levar em consideração as características das árvores a serem utilizadas, condições do solo e da área livre que seja compatível com o porte e outras exigências da espécie para crescimento da árvore (DE ANGELIS, 2000). 


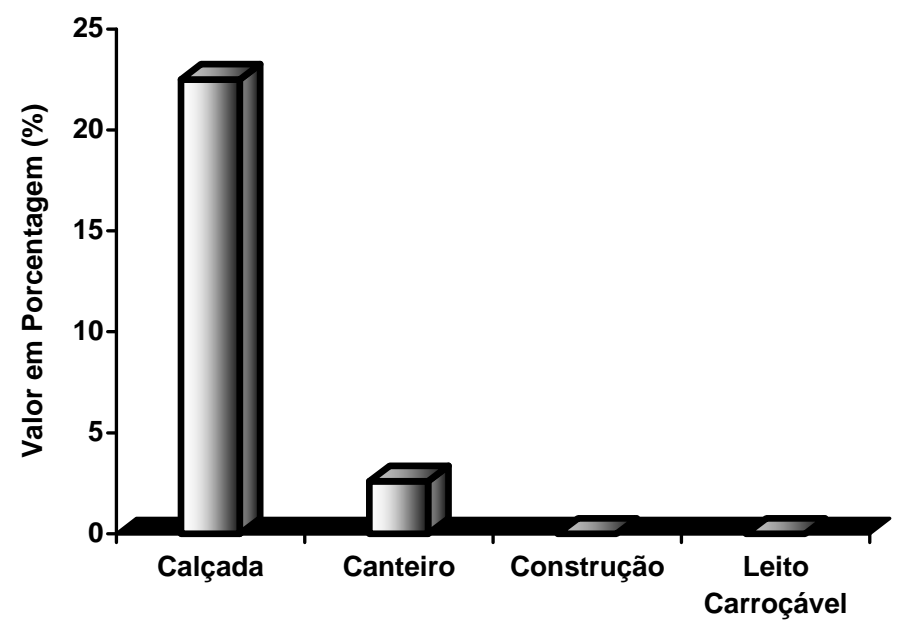

DAfloramento de raíz

FIGURA 15 - Local da via pública onde foi detectado afloramento de raiz.

FIGURE 15 - Location on public way where was detected root outcrop.

A Figura 16 mostra a porcentagem de interferências das redes de energia elétrica na arborização urbana do bairro São Judas Tadeu, pois $24,3 \%$ dos galhos das árvores estão em contato com fiação, o que pode provocar curto - circuito e desencadear desligamentos pelo sistema de proteção, além de ocasionar danos e acidentes. Também $24,3 \%$ das árvores pela tendência de seu crescimento entrarão em contato com a fiação, sendo então potencial em relação à mesma. Portanto, 51,4\% são de não existir possibilidades de contato, ou seja, as árvores não têm porte suficiente para alcançar a fiação, mesmo obedecendo a seu porte natural ou não estão próximas à fiação.

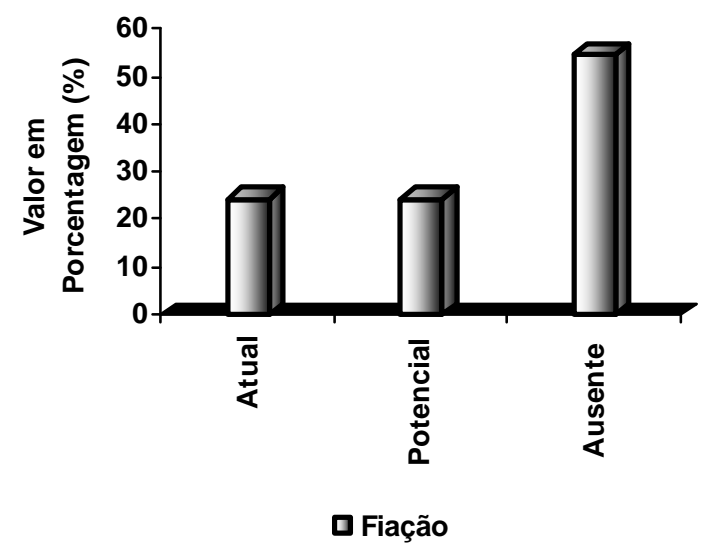

FIGURA 16 - Intervenção das árvores em relação à fiação existente ou previsível.

FIGURE 16 - Trees intervention related to existing or predictable power line. 
Segundo Silva et al. (2002) com relação ao posicionamento, se a favor ou contra a rede elétrica, o importante é levar em consideração o fato de que as árvores ainda poderão crescer e no futuro apresentar conflito com as redes elétricas e de telecomunicações. Segundo Bortoleto e Filho (2006), a arborização de Estância de Águas de São Pedro em alguns setores foram analisados interferência nas sinalizações públicas, onde foi priorizado a redução dos contatos atuais, recomendando a melhoria dos critérios de plantio (definição da localização), procurando preservar a arborização existente.

A Figura 17 mostra a interferência das árvores em muros ou construções, onde $43 \%$ das árvores estavam atuais na interferência, ou seja, o plantio estava muito próximo a muros e conseqüentemente próximo às residências, o que deve ser evitado, pois, as copas podem danificar telhados, entupir calhas e até mesmo prejudicar na incidência da luz solar no interior das moradias. E $27 \%$ das árvores era potencial para atingir muros e construções o que pode acarretar danos posteriormente. E 30\% das árvores não tinham nenhuma possibilidade de alcançar muros ou construções, pois o plantio não estava próximo aos mesmos ou devido ao porte de crescimento normal não atingem nenhum imóvel.

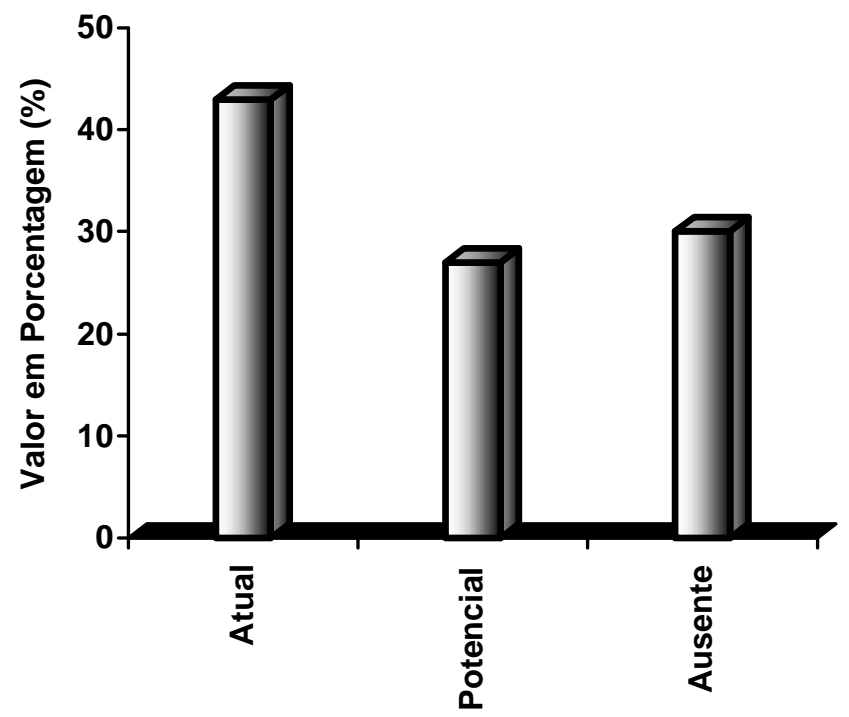

DMuro/Construção

FIGURA 17 - Interferência das árvores em muros ou construções.

FIGURE 17 - Interference of trees on walls or builds. 


\section{Definição de ações}

A Figura 18 mostra que a maioria das ações executadas nas árvores foram podas pesadas correspondente $37,2 \%$ dos casos encontrados, isso se explica porque as árvores estavam apresentando conflito com a rede e energia elétrica ou outros elementos urbanos. E 33,2\% a ação foi poda leve, sendo realizada para obtenção de uma copa adequada para o espaço disponível e até mesmo para eliminar as ramificações que dificultam a circulação de pedestres. E com 13,7 \% a ação foi de plantio, árvores em desenvolvimento; 1,3\% não foi encontrado nenhuma ação executada.

Segundo Christo e Dias (2006) a arborização urbana na cidade Prudentópolis, PR, existe uma grande necessidade de podas para corrigir os problemas advindos das deficiências das árvores. Esses problemas podem gerar conseqüências negativas para as fiações elétricas, telefônicas e, também, para a sinalização viária. Além disso, recomenda-se que as podas sejam realizadas por técnicos especializados para essas atividades, para minimizar os danos nas árvores e obter sucesso no procedimento, evitando comprometer o desenvolvimento satisfatório das espécies ao longo das vias públicas.

Para Oliveira (2005), as práticas de conservação da arborização urbana, a poda destaca-se, de modo especial, nas vias públicas com o objetivo de assegurar as funções desempenhadas pelas árvores no ambiente urbano em harmonia com edificações, equipamentos e redes de transmissão, indispensáveis à Cidade, garantindo a vitalidade das árvores e a segurança dos habitantes. O serviço de poda exige a assistência de profissionais qualificados, pois as árvores são organismos vivos que possuem mecanismos de defesa capazes de suportar este tipo de intervenção. Entretanto, uma poda mal executada, poderá causar danos irreversíveis ao vegetal e até levá-lo à morte. 


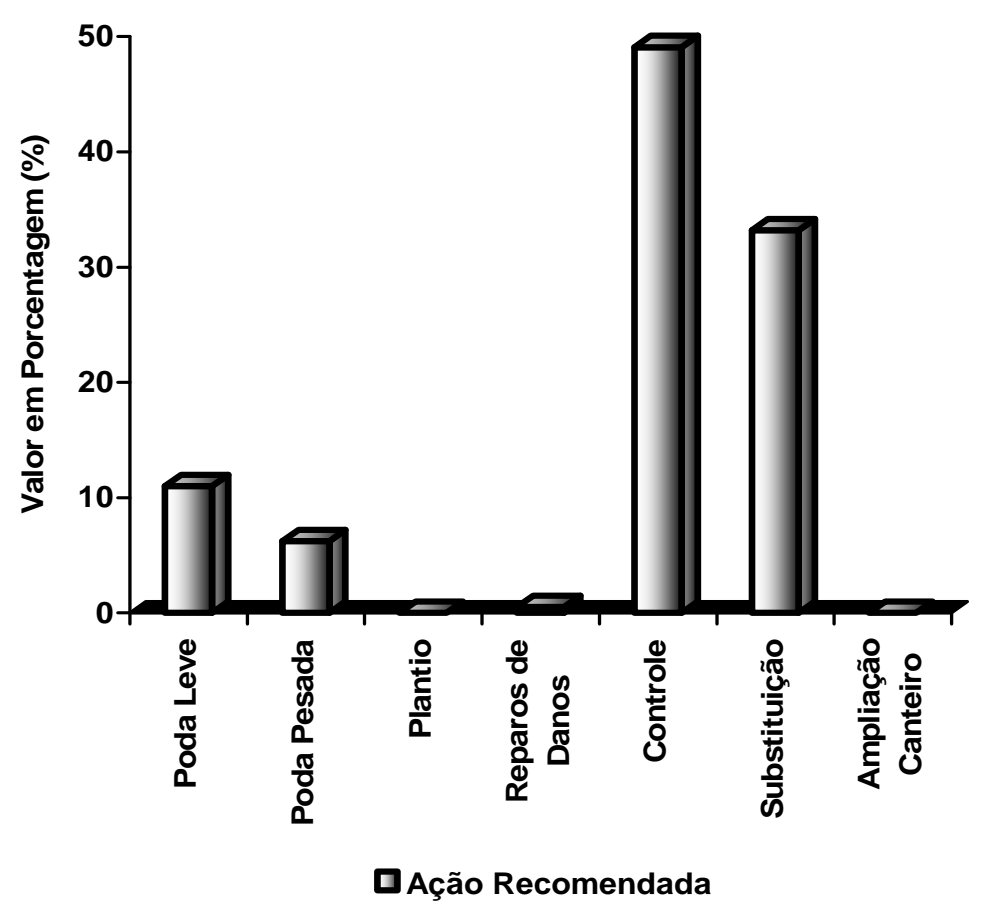

FIGURA 18 - Ação recomendada para espécies arbóreas do bairro São Judas Tadeu.

FIGURE 18 - Recommended action for arboreal species in neighborhood of São Judas Tadeu.

\section{CONSIDERAÇÕES FINAIS}

O município está localizado próximo ao Pantanal e abriga boa parte da avifauna em determinadas épocas do ano. Segundo Isernhagen et al., (2009) políticas implantação de arborização urbana devem se basear em espécies arbóreas nativas regionais criando mosaicos vegetacionais propícios para a sobrevivência da biota regional. Assim, toda iniciativa frente à arborização urbana deve levar em consideração inúmeros fatores, entre eles os que foram utilizados no presente trabalho. No município de Coxim existem leis e iniciativas do poder público protegendo a cidade e as árvores nela presentes. No entanto, novos trabalhos envolvendo a participação da população na arborização urbana devem ser realizados visando a construção de um Plano de Arborização Urbana de acordo com as necessidades locais. 


\section{REFERÊNCIAS BIBLIOGRÁFICAS}

ANDRADE, T. O. Inventário e análise da arborização viária da estância turística de Campos de Jordão, SP. São Paulo/SP, 2002. Dissertação. (Mestrado em Agronomia). ESALQ/USP - Escola Superior de Agricultura Luiz Queiroz, Universidade de São Paulo. 2002.

BORTOleto, S.; FILHO, D. F. S.; LIMA, A. M. L. P. Prioridades de manejo para a arborização viária da Estância de Águas de São Pedro-sp, por setores. Revista da Sociedade Brasileira de Arborização Urbana, Piracicaba, v. 1, n. 1, p. 62-73, 2006.

CHRISTO, J.A.; DIAS, A.N. - Inventário Florestal da Arborização Urbana do Centro da Cidade de Prudentópolis - PR. Revista Eletrônica Lato Sensu, v. 2, p.. 75-88, 2007.

COLETTO, E.P.; MULLER, N.G.; WOLSKI, S.S. Diagnóstico da arborização das vias publicas do município de Sete de Setembro-RS. Revista da Sociedade Brasileira de Arborização Urbana, Piracicaba, v. 3, p. 110-122, 2008.

COLTRI, P.P. et al. Arborização viária do centro de Piracicaba-SP e temperatura local: levantamento de dados e análise de imagens de satélite. In: CONGRESSO BRASILEIRO DE ARBORIZAÇÃO URBANA, 9, 2005, Belo Horizonte. Anais... Belo Horizonte: SBAU, 2005, (CD-ROM).

DANTAS, I. C.; SOUZA, C. M. C.. Arborização urbana na cidade de Campina Grande - PB: Inventário e suas espécies. Revista de Biologia e Ciências da Terra, João Pessoa. v. 4, n.2., p. 123-139, 2004.

DE ANGELIS, B. Praça no contexto das cidades o caso de Maringá/PR.. Tese (Doutorado em Geografia) - Faculdade de Filosofia, Letras e Ciências Humanas, Universidade de São Paulo, São Paulo: 2000. 
ENERSUL. Guia de Arborização Urbana, Campo Grande: Enersul, 2005, 56p.

FISCHER, G. R. Arborização Pública: a experiência de Joinville. In: ENCONTO NACIONAL SOBRE ARBORIZAÇÃO URBANA, 1, 1985, Porto Alegre. Anais... Porto Alegre, 1985. p.129-143.

FLORIANO, E. P. et al. Censo da arborização da região central da cidade de Horizontina, RS. Trabalho Técnico-científico n. 2, / Eduardo Pagel Floriano, Cibele Rosa Gracioli, Amarílio Motta Floriano, Rosana Maria Motta Floriano. Santa Rosa: Anorgs/Prefeitura municipal de Horizontina, 2004. 69p.

GREY, G.W.; DENEKE, F. J. Urban forestry. New York: John Wiley, 1978. 279p.

HASSE, I.; SHINOSAKA, T.J.; SILVA, L.M. Avaliação da presença de cupins na arborização da região central de Pato Branco-PR. Revista da Sociedade Brasileira de Arborização Urbana, Piracicaba, v. 3, n. 1, p. 9-18, 2008.

ISERNHAGEN, I.; Le BOURLEGAT, J.M.G.; CARBONI, M. Trazendo a riqueza arbórea regional para dentro das cidades: possibilidade, limitações e benefícios. Revista da Sociedade Brasileira de Arborização Urbana, Piracicaba, v. 4, p. 117-138, 2009.

LIMA, A.M.L.P et al. Problemas de utilização na conceituação de termos como espaços verdes e correlatos. In: CONGRESSO BRASILEIRO DE ARBORIZAÇÃO URBANA, 2, São Luis, MA,1994. Anais... São Luis, MA, SBAU, 1994, p. 538-550.

LORENZI, H. O homem deve se adaptar à árvore não ela ao homem. Folha do meio ambiente cultura viva. Brasília DF: 2001, no 120, p. 12-17.

MARTINS, C. S. Monitoramento da arborização das ruas de Belo Horizonte. In: CONGRESSO BRASILEIRO DE ARBORIZAÇÃO URBANA 2, 1994, São Luís, MA. Anais... São Luís, MA: SBAU, 1994, p. 421-430. 
MILANO, M. S. Avaliação quali-quantitativa e manejo da arborização urbana: exemplo Maringá-PR. Curitiba, 1988. 120 p. Tese (Doutorado em Engenharia Florestal). UFPR, Curitiba, 1988.

MILANO, M. S.; DALCIN, E. Arborização de Vias Públicas. Rio de Janeiro: Light 2000. 2000, 226p.

ODUM, E. P. Ecologia. Rio de Janeiro: Guanabara, 1988. 434p.

OLIVEIRA, F. B.; KAPPEL, R. B.; Incidência de ervas de passarinho na arborização de ruas de Porto Alegre. In: Congresso Brasileiro de Arborização Urbana, 2, 1994, São Luís, Anais... São Luís, 1994. p. 335- 346.

OLIVEIRA, I. L. Arborização Urbana, Paisagem e Biodiversidade, melhoria da qualidade de vida dos moradores de Cáceres- MT. Universidade do Estado de Mato Grosso - UNEMAT, 2005, pp. 1792-1799.

QUADROS, L.S.; FREI, F. Percepção ambiental dos residentes da cidade de Assis-SP com relação à arborização viária da Avenida Rui Barbosa. Revista da Sociedade Brasileira de Arborização Urbana, Piracicaba, v. 4, p. 16-34, 2009.

SANCHOTENE, M. C. C. Desenvolvimento e perspectivas da arborização urbana no Brasil. In: Congresso Brasileiro de Arborização Urbana, 2, 1994. São Luis, MA. Anais... São Luis, MA: SBAU, 1994.

SANTOS, N. R. Z.; TEIXEIRA, I. F. Levantamento quantitativo e qualitativo da arborização do bairro centro da cidade de Santa Maria - RS. In: ENCONTRO NACIONAL SOBRE ARBORIZAÇÃO URBANA, 3, 1990, Curitiba. Anais... Curitiba: FUPEF, 1990. p. 263-276.

SILVA FILHO, D.F. da. Cadastramento informatizado, sistematização e análise da arborização das vias públicas da área urbana do município de Jaboticabal, SP. 81p. Dissertação (Mestrado) - Faculdade de Ciências Agrárias e Veterinárias, Universidade Estadual Paulista “Júlio de Mesquita Filho", Jaboticabal, 2002. 
SILVA JUNIOR, O. A. B.; MÔNICO, M. O. M. Arborização em Harmonia com a Infraestrutura Urbana. In: 1a Semana de Meio Ambiente. Prefeitura de Guarulhos. Secretaria de Meio Ambiente, 1994.

SILVA, L. M. et al.. Arborização de vias públicas e a utilização de espécies exóticas: o caso do bairro Centro de Pato Branco/PR. Scientia Agraria, v.8, p.91 - 97, 2007.

SILVA, L.M. et al. Inventário da arborização em duas vias de Mariópolis/PR. Revista da Sociedade Brasileira de Arborização Urbana, Piracicaba. v. 3, n.1, p. 36-53, 2008.

SILVA FILHO, D.F. et al. Levantamento do potencial de arborização e proposta para três bairros no município de Piracicaba/SP, Brasil. Revista da Sociedade Brasileira de Arborização Urbana, v. 3, n.4, p. 20-39, 2008.

SIRKIS, A. Ecologia urbana e poder local. Rio de Janeiro: Ondazul, 1999.

TAKAHASHI, L. Y. 1994. Arborização urbana: inventário. In: CONGRESSO BRASILEIRO DE ARBORIZAÇÃo URBANA, 2, 1994, São Luís. Anais... São Luís, 1994, p. 193-198.

VITÓRIA. Plano Diretor de Arborização e Áreas Verdes. Secretaria Municipal do Meio Ambiente, Secretaria Municipal de Serviços Urbanos.. Vitoria, 1992. 98 p. 